\title{
Assessment of the sensory and physical limitations imposed by leprosy in a Brazilian Amazon Population
}

\author{
Cintia Yolette Urbano Pauxis Aben-Athar ${ }^{[1]}$, Sandra Souza Lima ${ }^{[1]}$, \\ Ricardo Ishak ${ }^{[1]}$ and Antonio Carlos Rosário Vallinoto ${ }^{[1]}$
}

[1]. Laboratório de Virologia, Instituto de Ciências Biológicas, Universidade Federal do Pará, Belém, PA, Brasil.

\begin{abstract}
Introduction: Leprosy often results in sensory and physical limitations. This study aimed to evaluate these limitations using a quantitative approach in leprosy patients in Belém (Pará, Brazil). Methods: This epidemiological, cross-sectional study measured the sensory impairment of smell and taste through the use of a questionnaire and evaluated activity limitations of daily life imposed by leprosy through the Screening of Activity Limitation and Safety Awareness (SALSA) Scale. Data were collected from 84 patients and associations between the degree of disability and clinical and epidemiological characteristics were assessed. Results: The majority of patients were men $(64.3 \%)$, married $(52.4 \%)$, age $31-40$ years old $(26.2 \%)$, had primary education $(50 \%)$, and were independent laborers $(36.9 \%)$. The multibacillary operational classification $(81 \%)$, borderline clinical form $(57.1 \%)$, and 0 degrees of physical disability (41.7\%) were predominant. SALSA scores ranged from 17 to 59 points, and being without limitations was predominant (53.6\%). The risk awareness score ranged from 0 to 8 , with a score of 0 (no awareness of risk) being the most common (56\%). Evaluation of smell and taste sensory sensitivities revealed that $70.2 \%$ did not experience these sensory changes. Patients with leprosy reactions were 7 times more likely to develop activity limitations, and those who had physical disabilities were approximately four times more likely to develop a clinical picture of activity limitations. Conclusions: Most patients showed no sensory changes, but patients with leprosy reactions were significantly more likely to develop activity limitations. Finally, further studies should be performed, assessing a higher number of patients to confirm the present results.
\end{abstract}

Keywords: Leprosy. SALSA scale. Physical disability. Smell. Taste.

\section{INTRODUCTION}

Leprosy is an ancient disease and has been the subject of prejudice, discrimination, and social exclusion from biblical times to the present day ${ }^{1}$. In general, clinical manifestations are characterized by neural and/or skin impairment, which may be unobtrusive and imperceptible at disease onset ${ }^{2}$. A vigilant attitude should be maintained towards physical changes from leprosy infection. Significant physical impairments from leprosy include neural impairment, changes in the prominence of cranial nerves caused by lesions in the oral and nasal cavities, and oromyofacial alterations that damage the voice, the hearing, and the functions of the stomatognathic system ${ }^{3}$.

The Screening of Activity Limitation and Safety Awareness (SALSA) scale is an instrument used for measuring activity limitations based on the International Classification of Functioning, Disability, and Health that enables more accurate clinical observation of the rehabilitation of leprosy patients. The

Corresponding author: Dr. Antonio Carlos Rosário Vallinoto.

e-mail: vallinoto@ufpa.br

Received 28 November 2016

Accepted 6 April 2017
SALSA evaluates the degree of sensitivity impairment resulting from peripheral neuropathies and risk awareness of patients on conditions that may affect their physical and mental integrity. Furthermore, it is the only instrument to address patient risk awareness, an important capacity in the context of leprosy pathology $y^{4,5,6}$.

The SALSA scale is composed of 20 questions, including questions evaluating mechanical skills used to perform routine activities that require preserved neural functions. The SALSA scale provides a novel and useful way to evaluate leprosy patients but is not currently used in the care of patients with leprosy in the City of Belém, Pará (PA), Brazil ${ }^{6,7}$.

The present study aimed to describe sensory impairment of smell and taste through the use of a novel questionnaire and evaluate activity limitations of daily life imposed by leprosy through the SALSA scale among leprosy patients residing in the City of Belém, PA.

\section{METHODS}

Study population

This was a descriptive epidemiological, cross-sectional study with a quantitative approach. The study was conducted in the 11 Municipal Health Unit (MHUs) of Belém that most often 
reported new cases of leprosy by operational class in a historical series from 2008-2012: the Guamá MHU (Unidade Municipal de Saúde do Guamá), the Jurunas Basic Health Unit (Unidade Básica de Saúde do Jurunas), the Marambaia MHU (Unidade Municipal de Saúde Marambaia), the Icoaraci MHU (Unidade Municipal de Saúde de Icoaraci), the Tapanã Basic Health Unit (Unidade Básica de Saúde do Tapanã), the Condor MHU (Unidade Municipal de Saúde da Condor), the Terra Firme MHU (Unidade Municipal de Saúde da Terra Firme), the Fátima MHU (Unidade Municipal de Saúde de Fátima), the Curió Health Center (Centro de Saúde do Curió), the Tavares Bastos MHU (Unidade Municipal de Saúde Tavares Bastos), and the Cremação MHU (Unidade Municipal de Saúde da Cremação).

To be included in the study, patients could be with or without leprosy reactions, were enrolled in the control program (Leprosy Prevention and Control Program of the Brazilian Health Ministry), were under treatment in the selected MHUs, were older than 18 years of age, and had agreed to participate in the study.

\section{Ethical considerations}

This study was submitted to and approved by the Research Ethics Committee of the Institute of Health Sciences, Federal University of Pará [Universidade Federal do Pará (UFPA)] (protocol no. 623,894), following the Guidelines and Rules for Research Involving Humans (Resolution 196 of the National Council of Health, Ministry of Health). All patients were informed with a written document and those who agreed to participate in the study provided written informed consent.

\section{Procedures}

The field study was conducted after prior authorization from the Belém Municipal Health Secretariat (Secretaria Municipal de Saúde de Belém) and the management of each MHU. The patients were briefed regarding the purpose of the study. The instruments used for data collection were the I) the SALSA scale and II) a novel interview protocol created by our research team. For the SALSA scale, a patient was categorized as with limitations if they reported a score $\geq 25$ and without limitations if they reported a score $<25$. The novel interview protocol asked epidemiological and clinical questions with a focus on assessing alterations in sensitivity of smell and taste. There were two questions in the interview script unique for this purpose: one asked if a patient noticed any alteration in smell that would make it difficult to smell perfume or food, and a second question assessed if the patient noticed any changes that made it difficult to taste food. Patients were interviewed and assessed by a trained member of the research team.

\section{Statistics}

The data obtained were stored in Microsoft Access 2010 (Santa Rosa, California, United States). Statistical analyses were performed using Bioestat $5.3^{8}$. The Fisher's exact test and G-Test were used to examine associations between the degree of disability measured via the SALSA scale and clinical and epidemiological characteristics. Odds ratios were calculated to estimate the probability of activity limitations occurring in relation to leprosy reactions and degree of physical disability. The significance level used for all tests was 0.05 .

\section{RESULTS}

The study included 84 patients with leprosy from 11 MHUs of Belém, PA. In the study group, $19(22.6 \%)$ patients were from the MHU of Guamá, 17 (20.2\%) from Jurunas, 13 (15.5\%) from Tapanã, 9 (10.7\%) from Marambaia, 7 (8.3\%) from Icoaraci, 5 (6\%) from Terra Firme, 5 (6\%) from Tavares Bastos, 4 (4.8\%) from Condor, 3 (3.6\%) from Curió, 1 (1.2\%) from Cremação, and $1(1.2 \%)$ from Fátima.

More than half of the participants (64.3\%) were male and $26.2 \%$ were in the 31 - to 40 -year-old age group. Notably, $42(50 \%)$ patients had only primary education and only $7(8.3 \%)$ patients had completed higher education. The most frequent civil status was married (52.4\%). An analysis of patient occupation revealed that $31(36.9 \%)$ were in the independent laborer category, while only $2(2.4 \%)$ were unemployed at the time of the study. Regarding family income, 34 (40.5\%) patients had a family income of less than one minimum monthly wage.

A total of $74(88.1 \%)$ patients were presently undergoing their first treatment for leprosy. Regarding operational classification, multibacillary leprosy was found in 68 (81\%) patients, and the borderline clinical form was the most frequent (57.1\%). Only 16 patients presented with leprosy reaction, $14(16.7 \%)$ with type 1 and 2 (2.4\%) with type 2; all 16 patients were treated with prednisone.

Some type of leprosy-related health problem was reported by $72(85.7 \%)$ patients. Of these patients, $54(64.3 \%)$ had numbness and tingling in the feet; the next most common problem was numbness and tingling in the hands (58.3\%). In addition, $68(81 \%)$ patients were aware of the possibility of becoming physically disabled from leprosy infection.

Less than half of the patients (41.7\%) had no disability at the time of the study, although 31 (36.9\%) had not been evaluated for disability. A majority of respondents (59.5\%) had undergone some change in lifestyle due to leprosy. It was also found that 64 (76.2\%) participants had been informed about Prevention of Disability techniques; however, 68 (81\%) had not been informed about performing exercises for the hands and feet. Participants reported that the most common guidance received was in the category other, which denoted do not sunbathe.

SALSA scores varied between 17 and 59; the most frequent scores were 19, 18, and 21 (Figure 1). More than half of the participants $(53.6 \%)$ did not have any activity limitations, $27(32.1 \%)$ had mild limitations, and none of the subjects had developed very severe limitations (Table 1).

When SALSA scale scores were examined with degrees of disability, some patients with grade 0 physical disability had mild and moderate activity limitation scores. Some of the patients with grade 2 physical disability had activity scores in the 'without limitations' and 'mild limitations' categories.

The risk awareness score ranged from 0 to $8 ; 47$ (56\%) patients had a score of 0 , indicating they had no risk awareness. The second most frequent score was $1(15.5 \%)$, followed by the scores $3(14.3 \%), 4(7.1 \%)$, and $8(1.2 \%)$.

There were no associations between activity limitation status and gender, age, operational classification, or clinical form 


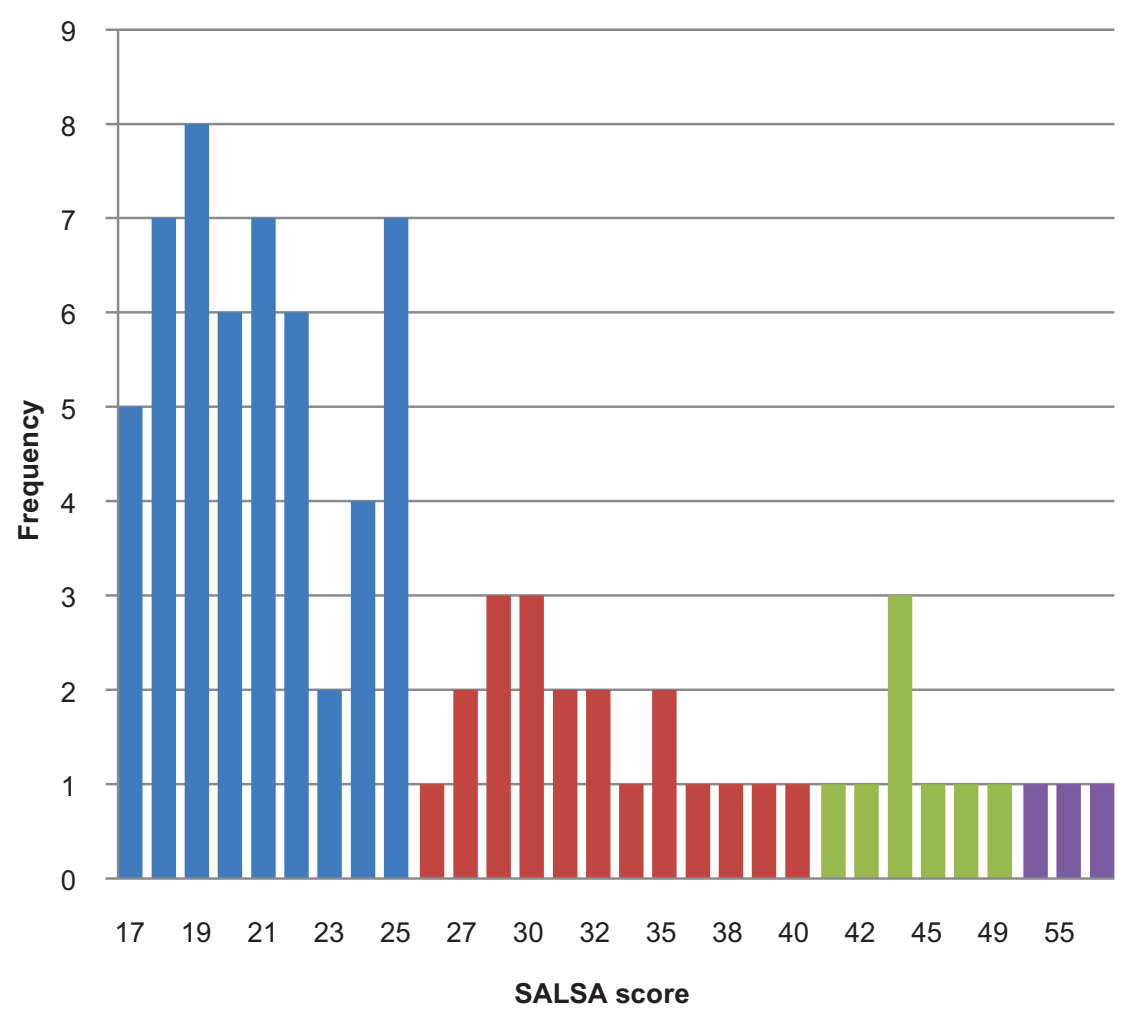

No Significant Limitation

Mild Limitation

Moderate Limitation

Severe Limitation

FIGURE 1 - SALSA scale score frequency distribution by limitation category, municipality of Belém, Pará, Brazil, 2014. SALSA: Screening of Activity Limitation and Safety Awareness.

of leprosy. However, there were associations between activity limitations and both physical disability and leprosy reactions. Patients with leprosy reactions were 7 times more likely to develop activity limitations than those without reactions. Patients who developed physical disability were 4 times more likely to develop limitations in activities of daily living than those who had no disability (Table 2).

Two sensory parameters, smell and taste, were evaluated to complement the SALSA scale physical evaluation. Patients were divided grouped as with sensory changes or without sensory changes; a majority ( $70.2 \%$ ) of patients were categorized as without sensory changes. We found no significant associations between any sample demographics and sensory change status.

\section{DIscussion}

The epidemiological data in this study are similar to those found in previously published literature ${ }^{9,10}$. We found that leprosy occurred predominantly in males, and more frequently in young adults. These findings indicate that the individuals most commonly affected by leprosy are likely an economically active population. This observation is of significant importance because leprosy is a disease with a high propensity for disability, which interferes with a patient's work and social life, and can lead to economic losses and psychological trauma ${ }^{11}$.
TABLE 1

Distribution of leprosy patients by SALSA scale score, municipality of Belém, Pará, Brazil, 2014

\begin{tabular}{lcc}
\hline SALSA Score & Number & Percentage \\
\hline Limitations $(10-24)$ & 45 & 53.6 \\
Mild limitations (25 - 39) & 27 & 32.1 \\
Moderate limitations (40 - 49) & 9 & 10.7 \\
Severe limitations (50 - 59) & 3 & 3.6 \\
Very severe limitations (60 - 80) & 0 & 0.0 \\
\hline Total & $\mathbf{8 4}$ & $\mathbf{1 0 0 . 0}$ \\
\hline
\end{tabular}

SALSA: Screening of Activity Limitation and Safety Awareness.

There was a predominance of patients with educational attainment less than or equal to nine years of study. This finding is similar to that observed by Monteiro et al..$^{12}$, who also found a predominance of low educational attainment among their study population. Low educational attainment affects treatment adherence and can make it difficult to interpret instructions about disability prevention ${ }^{13}$.

A civil status of married was common in our study population, corroborating the findings of Correa et al. ${ }^{14}$. This 
TABLE 2

Association between clinical variables and prevalence of activity limitations obtained from SALSA scores, municipality of Belém, Pará, Brazil, 2014.

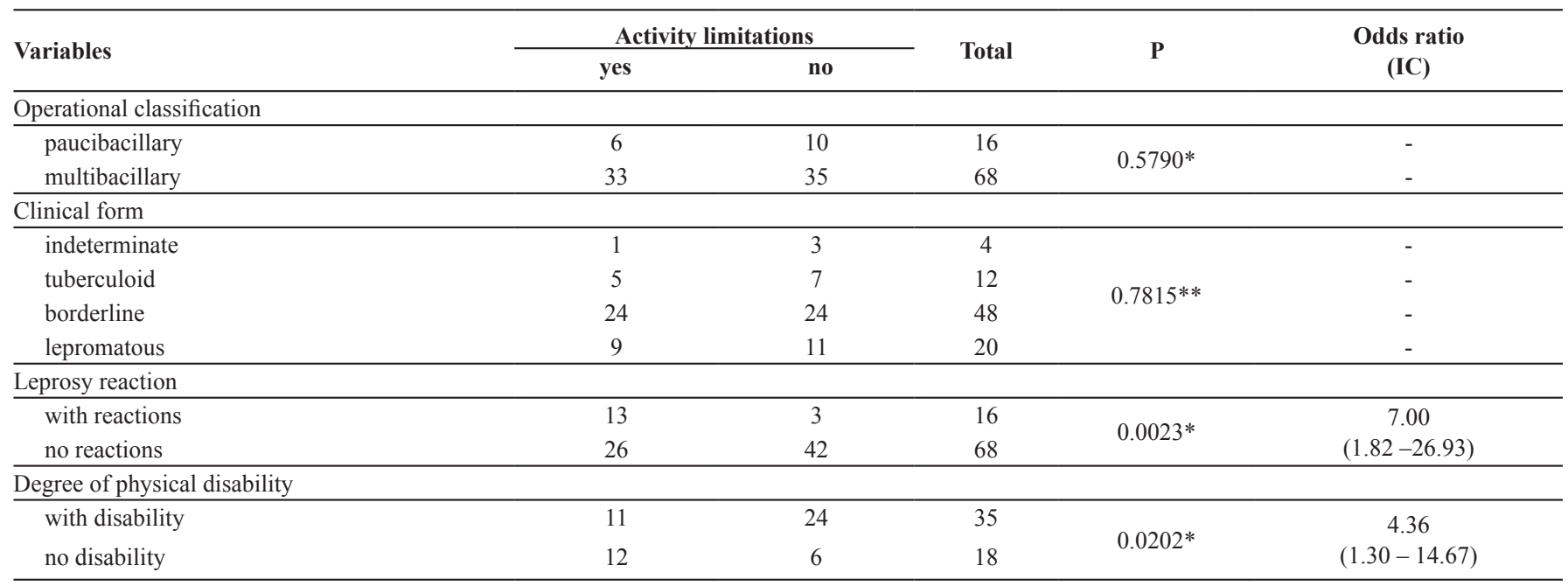

SALSA: Screening of Activity Limitation and Safety Awareness; IC: interval confiance. *Fisher's exact test. **G-Test.

finding indicates the potential need for family assistance since leprosy, and associated disability, may affect family relationships ${ }^{15}$. The independent laborer profession was the most frequent occupation reported in this study, as was the case in Batista et al. ${ }^{16}$. In most cases, this profession is associated with manual, heavy labor that generates low income ${ }^{16}$.

Multibacillary leprosy was the most frequent operational classification of leprosy reported by patients participating in this study. Similar results were found in Teixeira et $\mathrm{al}^{17}$. The predominance of multibacillary forms is due, among many factors, to delayed diagnosis, which affects maintenance of the epidemiological chain and can serve as a source of increased transmission ${ }^{14,17}$. The borderline clinical form was the most prevalent form of leprosy in this study, corroborating the results of Alves et al. ${ }^{18}$. It is known that the closer to the lepromatous pole, the greater the likelihood of developing disabilities ${ }^{19}$. The development of leprosy reaction type 1 or reverse reaction was observed in a majority of patients in this study, similar to results reported by Teixeira et al. ${ }^{17}$. Reactional states are the leading cause of nerve damage and physical disability caused by leprosy; therefore, monitoring and treating leprosy reactions is essential ${ }^{20}$.

With regard to physical disability, there was a higher frequency of patients with physical disability of grade 0 , a finding similar to that of Mesquita et al. ${ }^{21}$. However, some study patients had not been evaluated for physical disabilities, which may reflect the lack of health services in the city and potential non-compliance with established procedures for cases of leprosy. It is essential that technical limitations and/or inattention of professionals working in the Leprosy Prevention and Control Program (Programa de Prevenção e Controle de Hanseniase), along with monitoring and early diagnosis, be addressed to ensure a good prognosis for leprosy patients ${ }^{22}$. The recognition of flaws and limitations of health services and the creation of strategies to address these issues are vital challenges for the advancement of healthcare in Belém ${ }^{23}$.

The SALSA scale results showed that most respondents had no activity limitations, which differed from the findings of Ikehara et al. ${ }^{24}$. Cases with scores reflecting no limitations were the most frequent, followed by cases with scores reflecting mild limitations, a result similar to that reported by Silva et al. ${ }^{25}$.

The study participants did not achieve values close to 11 in their risk awareness scores, indicating a low level of awareness regarding the risks involved in activities of daily living. In addition, while $76.2 \%$ of patients in this study reported being given guidance about disability prevention, many found it difficult to list the guidance they received. Previous studies report similar results, which highlights the importance of providing proper and accessible guidance during health team consultations ${ }^{4,26,27}$. The literature shows that activity limitations in leprosy patients tend to increase with age ${ }^{28}$; however, this study did not find a significant association between age and activity limitations.

Regarding activity limitations and the presence of leprosy reactions, limitations were observed predominantly in patients with reactive states in this study. Individuals who developed leprosy reactions, regardless of type, were seven times more likely to develop physical activity limitations, underscoring the importance of adequate and vigilant care to identify cases with leprosy reactions. Leprosy reactions cause a high burden of both physical and emotional distress and are considered to be the leading cause of disability in patients with the disease ${ }^{29}$, therefore limiting the performance of activities of daily living and changing the patient's lifestyle.

It is believed that the greater the degree of physical disability, the greater the activity limitations, as seen in the present study. However, due to disagreements in both evaluation criteria and the classification of physical disabilities, other studies have not demonstrated the reliability of this relationship ${ }^{24}$. Divergences 
were observed in the correlation of patients with disability grades 0 and 2 and SALSA scores. Patients identified with grade 0 disability had reported SALSA scores above the scale cutoff for limitations, characterizing the presence of mild to moderate limitations. The same divergence was observed in patients with a diagnosis of grade 2 disability, often correlating with activity scores of no limitations and mild limitations.

Among the changes suffered by leprosy patients, sensory changes in smell and taste can significantly affect quality of life. Sensory changes were not observed in the patients interviewed in this study. However, the importance of the early detection of smell and taste disorders, which usually occur together, should be stressed to ensure that effective treatment is given to reduce symptom severity and avoid sequelae ${ }^{30}$.

It is assumed that the relationship between the degree of physical incapacity and limitations of activity measured by the SALSA scale would be proportional, and that patients with some degree of insufficiency should present some modification of the SALSA score for the limitation of physical activity due to the fact that leprosy patients often present with weakness. However, a divergence was found between the SALSA scale activity limitation scores and degree of physical disability in this study. Moreover, our results suggest that patients with physical disabilities were 4 times more likely to report activity limitations, and those who developed leprosy reactions were 7 times more likely to have activity limitations. This controversial finding may be a consequence of the development of unusual abilities, such as incorrect grasp patterns, which confers a certain degree of independence in activities.

Finally, the present study described, for the first time, sensory impairment of smell, taste, as well as activity limitations of daily life imposed by leprosy through the SALSA scale among leprosy patients residing in the City of Belém, PA. However, further studies should be performed, assessing a higher number of patients to confirm the present results.

\section{Acknowledgments}

We thank all of the patients who agreed to participate and the Municipal Health Secretariat of Belém for authorizing this study.

\section{Financial support}

This work was partially supported by grants from the Coordination for the Improvement of Higher Education Personnel (CAPES) and the Dean of Research and Graduate Studies, Federal University of Para (Pró-Reitoria de Pesquisa e Pós-Graduação - PROPESP/UFPA).

\section{Conflict of interest}

The authors declare that there is no conflict of interest.

\section{REFERENCES}

1. Scollard DM, Adams LB, Gillis TP, Krahenbuhl JL, Truman RW, Williams DL. The continuing challenges of leprosy. Clin Microbiol Rev. 2006;19(2):338-81.

2. Mendonça VA, Costa RD, Melo GEBA, Antunes CM, Teixeira AL. Imunologia da hanseníase. An Bras Dermatol. 2008;83(4):343-50.
3. Martins ACC, Castro JC, Moreira JS. Estudo Prospectivo de dez anos em endoscopia das cavidades nasais de pacientes com hanseníase. Rev Bras Otorrinolaringol. 2005;71(5):609-16.

4. Barbosa JC, Ramos Junior AN, Alencar MJF, Castro CGJ. Pósalta em hanseníase no Ceará: limitação da atividade funcional, consciência de risco e participação social. Rev Bras Enferm. 2008;61(spe):727-33.

5. Brakel WHV, Officer A. Approaches and tools for measuring disability in low and middle-income countries. Lepr Rev. 2008;79(1):50-64.

6. International Federation of Anti-Leprosy Associations (ILEP). The Screening Activity Limitation and Safety Awareness (SALSA). Scale: Users Manual. Version 1.1. 2010. Available from: https:// www.ilep.org.uk/library-resources/infolep-information-services/ subjectguides/salsa-scale/

7. Ebenso J, Fuzikawa P, Melchior H, Wexler R, Piefer A, Min CS, et al. The development of a short questionnaire for screening of activity limitation and safety awareness (SALSA) in clients affected by leprosy or diabetes. Disabil Rehabil. 2007;29(9):689-700.

8. Ayres M, Ayres Júnior M, Ayres DL, Santos AAS. Bioestat: aplicações estatísticas nas áreas das Ciências Biomédicas. Versão 5.0. Belém: Sociedade Civil Mamirauá, MCT-CNPq; 2007. 324 p.

9. Lana FCF, Amaral EP, Lanza FM, Saldanha ANSL. Desenvolvimento de incapacidades físicas decorrentes da hanseníase no Vale do Jequitinhonha, MG. Rev Lat-Am Enfermagem. 2008;16(6):993-7.

10. Saho M, Santana RM. Promovendo o auto-cuidado no controle da hanseníase. Rev Baiana Enferm. 2001;14(1):9-16.

11. Araújo AE, Aquino DM, Goulart IM, Pereira SR, Figueiredo IA, Serra HO, et al. Factors associated with neural alterations and physical disabilities in patients with leprosy in São Luis, State of Maranhão, Brazil. Rev Soc Bras Med Trop. 2014;47(4):490-7.

12. Monteiro LD, Alencar CHM, Barbosa JP, Braga KP, Castro MD, Heukelbach J. Incapacidades físicas em pessoas acometidas pela hanseníase no período pós-alta da poliquimioterapia em município no Norte do Brasil. Cad Saúde Pública 2013;29(5):909-20.

13. Miranzi SSC, Pereira LHM, Nunes AA. Perfil epidemiológico da hanseníase em um município brasileiro, no período de 2000 a 2006. Rev Soc Bras Med Trop 2010;43(1):62-7.

14. Corrêa RGCF, Aquino DMC, Caldas AJM, Amaral DKCR, França FS, Mesquita ERBP. Epidemiological, clinical, and operational aspects of leprosy patients assisted at a referral service in the state of Maranhão, Brazil. Rev Soc Bras Med Trop 2012; 45(1):89-94.

15. Sales JCS, Araújo MPR, Coelho MC, Luz VLES, Silva TCA, Silda Junior FG. Sexualidade de pessoas quem vivem com hanseníase: percepção e repercussões. Rev Enferm UFPE on line 2013;7(2):460-6.

16. Batista SE, Campos RX, Queiroz RCG, Siqueira SL, Pereira SM, Pacheco TJ, et al. Perfil sócio-demográfico e clínico-epidemiológico dos pacientes diagnosticados com hanseníase em Campos dos Goytacazes, RJ. Rev Bras Clin Med. 2011;9(2):101-6.

17. Teixeira MAG, Silveira VM, França ER. Características epidemiológicas das reações hansênicas em indivíduos paucibacilares e multibacilares, atendidos em dois centros de referência para hanseníase, na Cidade de Recife, Estado de Pernambuco. Rev Soc Bras Med Trop. 2010;43(3):287-92.

18. Alves CJM, Barreto JA, Fogagnolo L, Contin LA, Nassif PW. Avaliação do grau de incapacidade dos pacientes com diagnóstico de hanseníase em Serviço de Dermatologia do Estado de São Paulo 2010. Rev Soc Bras Med Trop. 2010; 43(4):460-1.

19. Antonio JR, Soubhia RMC, Paschoal VDA, Oliveira GB, Rossi NCP, Maciel MG, et al. Avaliação epidemiológica dos estados 
reacionais e incapacidades físicas em pacientes com hanseníase na cidade de São José do Rio Preto. Arq Ciênc Saúde. 2011;18(1):9-14.

20. Balagon MVF, Gelber RH, Abalos RM, Cellona RV. Reactions following completion of 1 and 2 year Multidrug Therapy (MDT). Am J Trop Med Hyg. 2010;83(3):637-44.

21. Mesquita R, Melo LTM, Vasconcelos RS, Soares DM, Felix GAA, Ferrer LPA, et al. Avaliação neurofuncional em pacientes com hanseníase. Rev Bras Promoç Saúde. 2014;27(2):247-55.

22. Nardi SMT, Paschoal VD, Saneta DMT. Frequência de avaliações e seu impacto na prevenção das incapacidades físicas durante o tratamento dos pacientes com hanseníase. Hansen Int. 2005;30(2):157-66.

23. Souza IA, Ayres JA, Meneguin S, Spagnolo RS. Autocuidado na percepção de pessoas com hanseníase sob a ótica da complexidade. Esc Anna Nery. 2014;18(3):510-4.

24. Ikehara E, Nardi SMT, Ferrigno ISV, Pedro HSP, Paschoal VDA. Escala SALSA e grau de incapacidades da Organização Mundial de Saúde: avaliação da limitação de atividades e deficiência na hanseníase. Acta Fisiatr. 2010;17(4):169-74.
25. Silva RSO, Serra SMF, Gonçalves EGR, Silva AR. Hanseníase no município de Buriticupu, estado do maranhão, Brasil: estudo de incapacidades em indivíduos no pós-alta. Hansen Int. 2012;37(2): 54-60.

26. Lima IB, Simpson CA, Cabral AMF. Activities limitation and social participation in patients with Hansen's disease. Rev Enferm UFPE. 2014;8(4):994-1001.

27. Samona J, Samona S, Samona C, Gopalakrishnan S, Shekhar $\mathrm{P}$, Kubern D, et al. An orthopedic, surgical, and epidemiological based investigation of leprosy, in the Tamil Nadu state of India. Adv Orthop. 2012;(2012):ID 783853.

28. Girardi DR, Bulegon H, Barra CMM. A decision support system based on leprosy scales. World Acad Sci Eng Technol. 2010;8(3): 193-7.

29. Souza LWF. Reações Hansênicas em pacientes em alta por cura pela poliquimioterapia. Rev Soc Bras Med Trop. 2010;43(6):737-9.

30. Palheta Neto FX, Targino MN, Peixoto VS, Alcântara FB, Jesus CC, Araújo DC, et al. Anormalidades sensoriais: olfato e paladar. Int Arch Otorhinolaryngol. 2011;15(3):350-8. 